\title{
Protective Capacity of Fusarium oxysporum Extract Against Gamma Radiation: A Study for some Biochemical Parameters in Albino Male Rats
}

\author{
Ezz El Arab, A. ${ }^{1}$, Hosam Eldin El-Sayyad, . ${ }^{2}$ Eskander, S.B. ${ }^{\text {* }}$ \\ (1) Radioisotopes Department, Egyptian Atomic Energy Authority, Cairo, Egypt \\ (2) Al-Ghad International College for Applied Medical Sciences - Al-Dmamm, KSA, Middle Eastern Regional Radioisotope Center \\ for Arab Countries, Cairo, Egypt (former)
}

\begin{tabular}{l} 
ART ICLE INFO \\
\hline Article history: \\
Received: $2^{\text {nd }}$ Feb. 2021 \\
Accepted: $1^{\text {st }}$ May 2021 \\
\hline Keywords: \\
8-radiation, \\
CBC, \\
Fusarium oxysporum extract, \\
Protective role, \\
Rats.
\end{tabular}

\begin{abstract}
The present work Aims to investigate the protective capacity of Fusarium oxysporum phosphate buffer extract (FO) against gamma radiation ( $\mathrm{\gamma}$-IR) based on evaluating the changes in some blood components in rat model. The variations in haematological and pairs of biochemical parameters were determined for $\mathbf{4 0}$ albino male rats divided into five groups : negative control, positive control, i.e. irradiated only, and three treated groups administrated increasing dose of (FO) before single four Gray (Gy) gamma irradiation dose. Three doses of FO extract $(0.15,0.3$ and $0.6 \mathrm{mg} / \mathrm{g}$ body mass) were chosen, as protective doses, for subsequent evaluating of its antioxidant activity and ameliorating capacity toward radiation-induced oxidative stress. The changes in the chosen parameters, due to administration of the FO and then 4Gy irradiation, were computed after 1, 2, 3 and 7 days. Total serum protein, albumin, total globulin, besides some parameters of complete blood count (CBC) were determined and the data obtained were analyzed to evaluate the capacity of FO to compensate the gamma irradiation injures.

The present work is assuming that biocomponents extracted from FO fungi have a protective role against gamma radiation which can establish protocols for medical management of radiation injuries based on natural medication.
\end{abstract}

\section{INTRODUCTION}

The impact of exposure to irradiation hazards is of great concern to the space exploration community as well as to patients subjected to radiotherapy in medical centers.[1] Commonly, man exposure to radiation happens as a result of radiotherapy treatments, working in nuclear establishments, nuclear battlefields and nuclear accidents.[2] This is in addition to the natural resources including cosmic rays from the surrounding ecologies which constitute about $82 \%$ of total exposure .Ionizing radiation (IR) harms biological tissues by exciting or ionizing their atoms and molecules. According to radiation dose and the biochemical processes, injures can be prompt that could be detected within minutes to weeks post exposure or delayed to several months to years later. [3] When living cells are exposed to ionizing radiation, they react in different ways which vary quantitatively and qualitatively based on the absorbed dose and the cell type and function that generally reflect injuries caused to well-defined cellular components and molecular structures. [4]

The mechanisms by which the gamma rays cause their harm effects can be attributed to the deterioration in cellular large molecules,[5] imbalance in ionic equilibrium and generation of reactive oxygen species (ROS).[6] Radiation damage is, to a large extent, caused by the overproduction of ROS, including superoxide anion $\left(\mathrm{O}^{2 \cdot^{-}}\right)$, hydroxyl radical $(\cdot \mathrm{OH})$, and hydrogen peroxide $\left(\mathrm{H}_{2} \mathrm{O}_{2}\right)$, that decrease the levels of antioxidants, resulting in oxidative stress and cellular damage. ROS cause damage by reacting with cellular macromolecules such as nucleotides in nucleic acids, polyunsaturated fatty acids found in cellular membranes, and sulfhydryl bonds in proteins. If this damage is irreparable, then injury, mutagenesis, carcinogenesis, accelerated senescence, and cell death can occur.[7] Ionizing radiations interact with biological systems, also, through free radicals generated by water radiolysis. This indirect 
action plays an important role in the induction of oxidative stress leading to cellular damage and organ dysfunction [8-10]. However, in medicine, there is a limited knowledge on the levels of chemicals, enzymes, and organic waste products that are normally found in the blood after irradiating with different gamma radiation doses.[11] Plants and all living organisms produce countless natural materials addressing their survival, defence, nutrition, and even growth.[12-14] Among those materials are the phenolic compounds such as phenols, flavonoids, coumarins, quinones, saponins, and xanthones, the most abundant, besides alkaloids, lectins, polypeptides, terpenoids, and essential oils.[14-17] Published studies indicated that the aqueous extracts of some plants and fungi have potent antioxidant activity.[18] The antioxidant activity is attributed to the wide range ofthe phenolic compounds in their extracts.[19-23] Fungal -derived extracts and related phytochemicals have gained a particular attention by many researchers concerning their protective role against ionizing radiation.

The CBC and pairs of biochemical parameters can be applied to predict the gamma irradiation exposure injures and the protective improvements due to FO administrations. Those tests are inexpensive, widely available, and easy to interpret.

The objective of this study is to evaluate the protective capacity of Fusarium oxysporum phosphate buffer extract, $(F O)$, against the gamma irradiation impacts in albino male rats.

\section{EXPERIMENTAL APPROACH}

\section{Fusarium oxysporum fungus}

Fusarium oxysporum fungi were collected from a near soil. The isolated strains were checked up using optical microscope (MEIJI modal ML 2100). The fungi were characterized by their white colours and distinguished colonies' morphology. Moreover, the fungi were characterized by presences of their spores and the unique shape of the cells.

\section{Cultivation of Fusarium oxysporum fungi}

Erlenmeyer flask (250 ml capacity) containing 100 $\mathrm{ml}$ Czapek's sucrose liquid medium was inoculated with Fusarium oxysporum fungi disc $(\sim 0.5 \mathrm{~cm}$ diameter). The flask was incubated at $25{ }^{\circ} \mathrm{C}$ for ten days, then filtrated and the acquired mycelia were washed thoroughly with distilled water many times before their filtration using filter paper Whatman GF/C circle $47 \mathrm{~mm}$ (Cat \#1822 047), England. The obtained mycelia were kept for the subsequent treatment.

\section{Phosphate Buffer Extraction of Fusarium Oxysporum components}

Fusarium oxysporum fungal mats (one g each) were mixed with $10 \mathrm{ml}$ of $0.01 \mathrm{M}$ phosphate buffer $(\mathrm{pH} 7.0)$ in a glass mortar and completely ground. The obtained mixtures were squeezed through several layers of cheese cloth. The filtrates were further clarified by centrifugation at $10,000 \mathrm{rpm}$ for 20 minutes at $-4{ }^{\circ} \mathrm{C}$ using Sigma 2k15-USA centrifuge. The reached clear filtrates were stored at $-10{ }^{\circ} \mathrm{C}$ for subsequent use.

\section{Gamma Irradiation Source}

A radiocesium gamma cell used for animals' irradiation was the cell-40 at the National Center for Radiation Research and Technology (NCRRT), Egyptian Atomic Energy Authority (EAEA), based on Cs-137 as a gamma source at $0.84 \mathrm{~Gy} / \mathrm{min}$. dose rate.

\section{Grouping and Treatment of Adult Male Albino Rats}

Forty adult albino male rats, Rattus norvegicus, weighing 160-180 g, were purchased from the National Research Center animal house, Giza, Egypt. The rats were let to steadiness for one week before grouping. The rats were then, randomly arranged into five groups; eight animals each, housed in a plastic cage. At the end of equilibrium period, the rat groups were subjected to various treatments following Table (1).

Post irradiation, the animals in the all 5 groups were returned back to their cages and followed up to one week, during this period, blood samples were collected after one day, two, three and seven days. A CBC in addition to total serum protein, serum albumin and serum total globulin contents were determined after 1,2, 3 and then 7 days from irradiation and FO extract administration to all groups.

Table (1): The various rat groups handled

\begin{tabular}{|c|c|c|}
\hline \multicolumn{3}{|c|}{ Rat group Treatment } \\
\hline Group 1 & $\begin{array}{l}\text { Control group, fed on normal diet and } \\
\text { freely }\end{array}$ & drink tap water \\
\hline Group 2 & Subjected to $4 \mathrm{~Gy}$ single dose $\gamma$ - Irradia & tion \\
\hline Group 3 & $\begin{array}{l}\text { Administrated } 0.15 \mathrm{mg} / \mathrm{g}^{*} \text { single dose } \\
\text { extract, irradiated } * *\end{array}$ & FO phosphate \\
\hline Group 4 & $\begin{array}{l}\text { Administrated } 0.3 \mathrm{mg} / \mathrm{g} * \text { single dose } \\
\text { extract, irradiated } * *\end{array}$ & FO phosphate \\
\hline Group 5 & $\begin{array}{l}\text { Administrated } 0.6 \mathrm{mg} / \mathrm{g} * \text { single dose } \\
\text { extract, irradiated } * *\end{array}$ & FO phosphate \\
\hline
\end{tabular}




\subsection{Evaluation of the Biochemical Parameters}

The red blood cells (RBCs) and white blood cells (WBCs) counts were evaluated based on the improved Neubauer haemocytometer method. The haemoglobin (Hb) concentration was determined according to Jain procedure (Jain,1986) [24] using cyanomethaemoglobin technique. Schilling method of differential leukocytes count was applied to evaluate the distribution of the various WBCs fractions. Mitruka \& Rawnsley approach was ,also, applied to compute the mean corpuscular volume (MCV), mean corpuscular haemoglobin $(\mathrm{MCH})$ and mean corpuscular haemoglobin concentration (MCHC).[25] On the other hand, total serum protein , albumin and total globulin were evaluated followingthe method described by Kaplan and Savory.[26]

\section{Ethical Clearance and Approval}

Procedures involving animals and their care were conducted in conformity with international laws and policies.The rats were handled according to the International Guiding Principles for Biochemical Research Involving Animals -2012, and the experimental procedures were approved by the Research Ethics Committee of the National Center for Radiation Research and Technology (REC-NCRRT), Egyptian Atomic Energy Authority.

The rats were housed in clean plastic cages, having wood saw dust mats, in conventional animal house that permit $100 \%$ fresh air circulation. The mean ambienttemperature in the housing facility was $28{ }^{\circ} \mathrm{C}$, ranging between $26-32{ }^{\circ} \mathrm{C}$, and the mean relative humidity was $60 \%(50-70 \%)$ with 12 hours light /12 hours dark cycle. The animals were freely fed on a normal rodent pallets diet and clean water offered by ad-libitum throughout the whole experimental period.

\section{Statistical Analysis}

All data were expressed as the mean \pm standard error of mean (SEM) from three independent samples. The experimental data obtained were fitted based on polynomial trend using R-square regression analysis.

The goodness of the model can be checked by the determination of the coefficients $\left(R^{2}\right)$. The values of the determination coefficient $R^{2}$ when near unity suggested that the total variations in data are attributed to the independent variables and only very less of the total variation cannot be explained by the model.

\section{RESULTS AND DISCUSSIONS}

Fusarium oxysporum extract assumes to enhance therats' immune systems as it has many antioxidant potentialingredients. It can mitigate the irradiationinduced alterations and can heal many of the harmful injures due to gamma ray exposure.Therefore, Fusarium oxysporum extract can be applied as an adjuvant biomedication during radiotherapy treatment for example.

Figures (1-11) show the changes in most interesting haematological parameters in male rats as function of 4 Gy single dose gamma irradiation and administrating increasing doses of Fusarium oxysporum extract (mg/g rat's body mass).

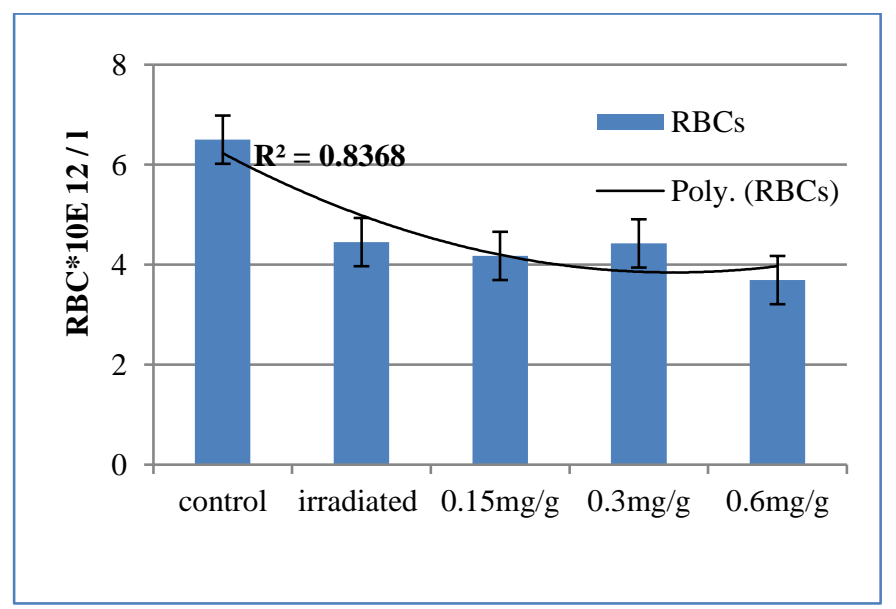

Fig. (1): The changes in the red blood cells (counts /) as functions of gamma irradiation and post administration of increasing doses of Fusarium oxysporum extract $(\mathrm{mg} / \mathrm{g}$ rat's body mass). Error bars indicate standard error of mean values

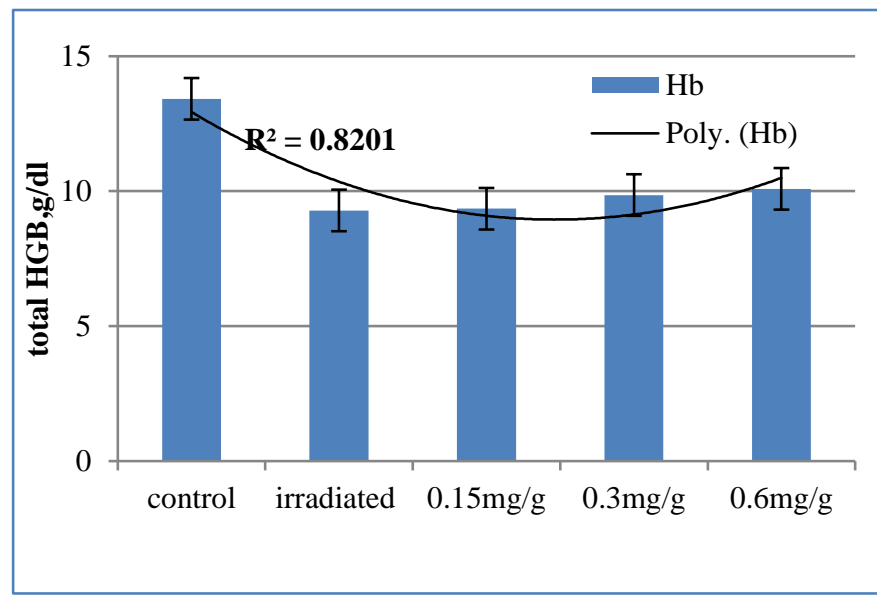

Fig. (2): The changes in the haemoglobin content (g/dl) as functions of gamma irradiation and post administration of increasing doses of Fusarium oxysporum extract (mg/ g rat's body mass). Error bars indicate standard error of mean values. 


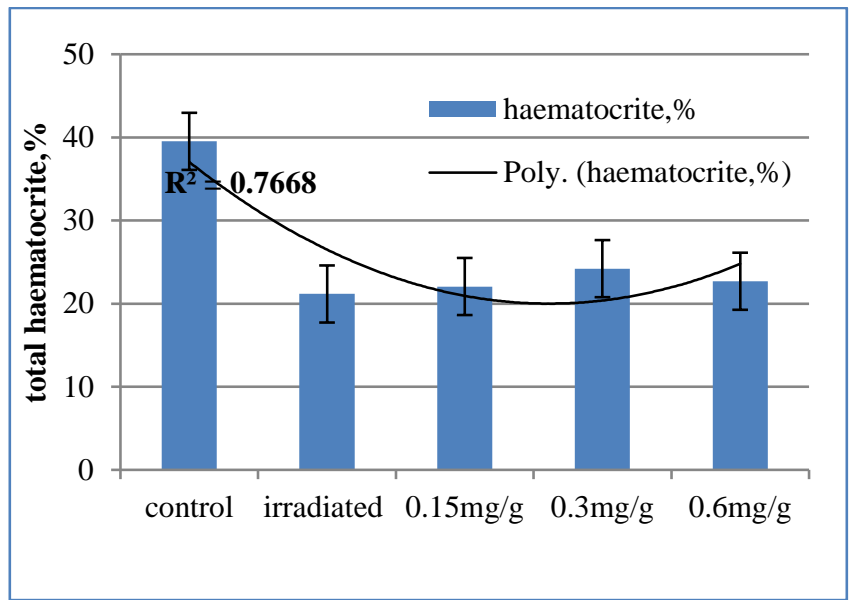

Fig. (3): The changes in the total haematocrite (\%) as functions of gamma irradiation and post administration of increasing doses of Fusarium oxysporum extract (mg/ g rat's body mass). Error bars indicate standard error of mean values.

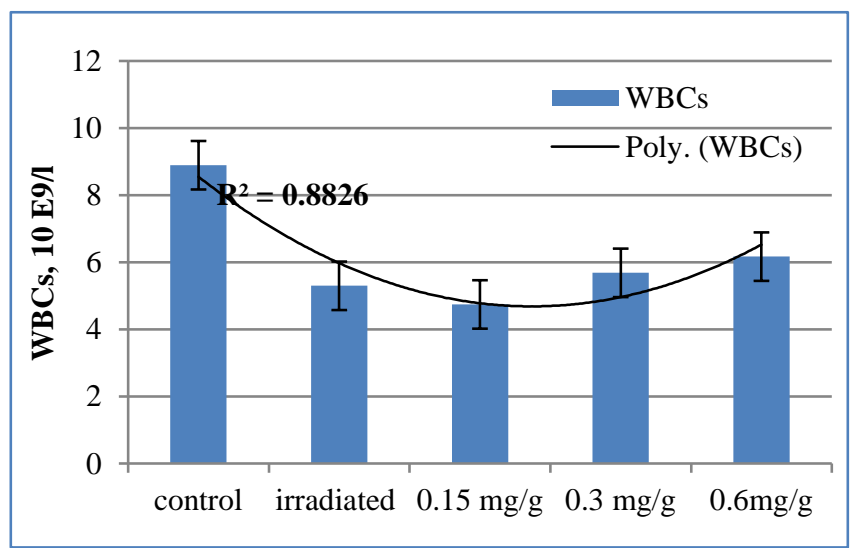

Fig. (4): The changes in the white blood cells (10 E9/l) as functions of gamma irradiation and post administration of increasing doses of Fusarium oxysporum extract (mg/ g rat's body mass). Error bars indicate standard error of mean values.

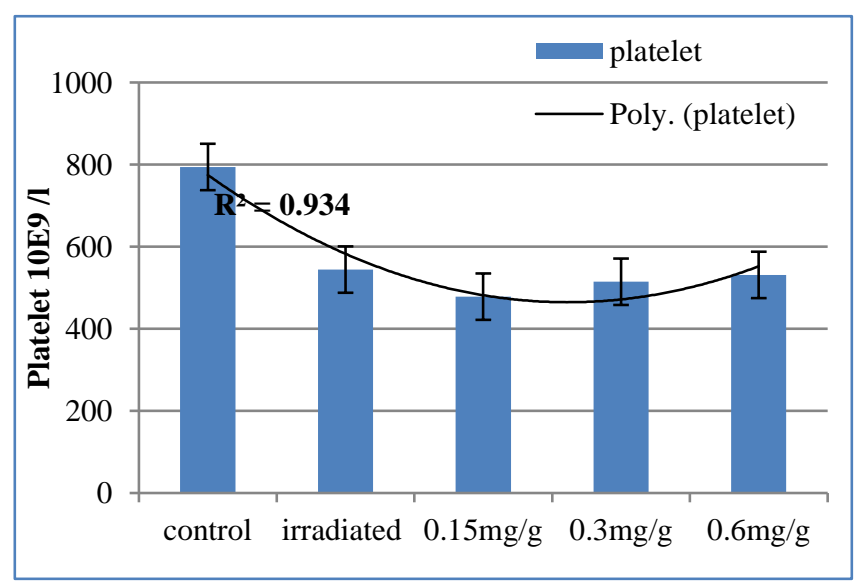

Fig. (5): The changes in the platelet count (10 E9/I) as functions of gamma irradiation and post administration of increasing doses of Fusarium oxysporum extract (mg/ g rat's body mass). Error bars indicate standard error of mean values.

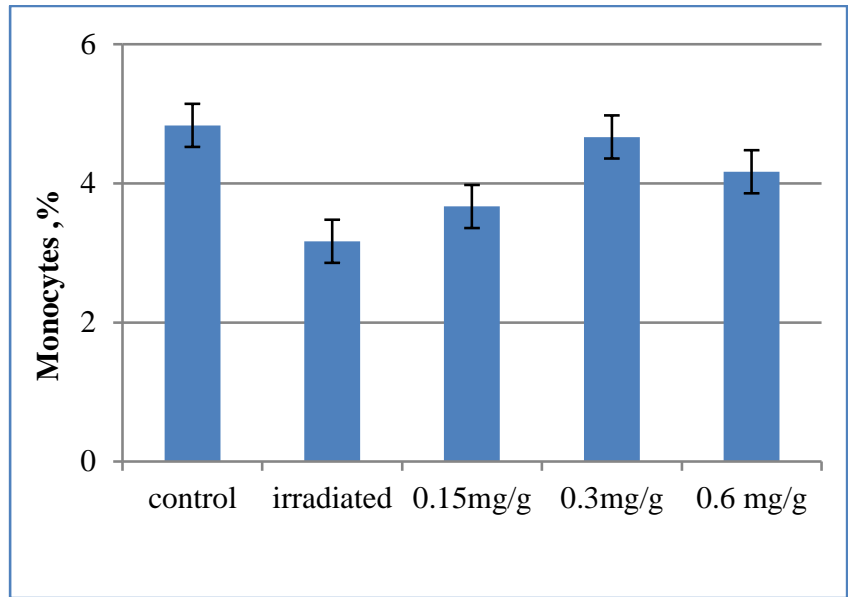

Fig. (6): The changes in the monocytes (\%) as functions of gamma irradiation and post administration of increasing doses of Fusarium oxysporum extract (mg/ g rat's body mass). Error bars indicate standard error of mean values.

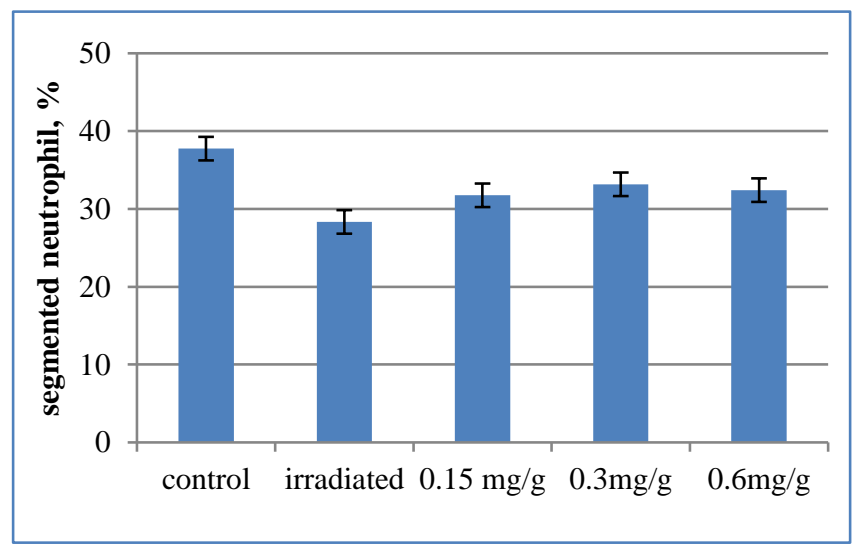

Fig. (7): The changes in the Segmented Neutrophil (\%) as functions of gamma irradiation and post administration of increasing doses of Fusarium oxysporumextract (mg/ g rat's body mass). Error bars indicate standard error of mean values.

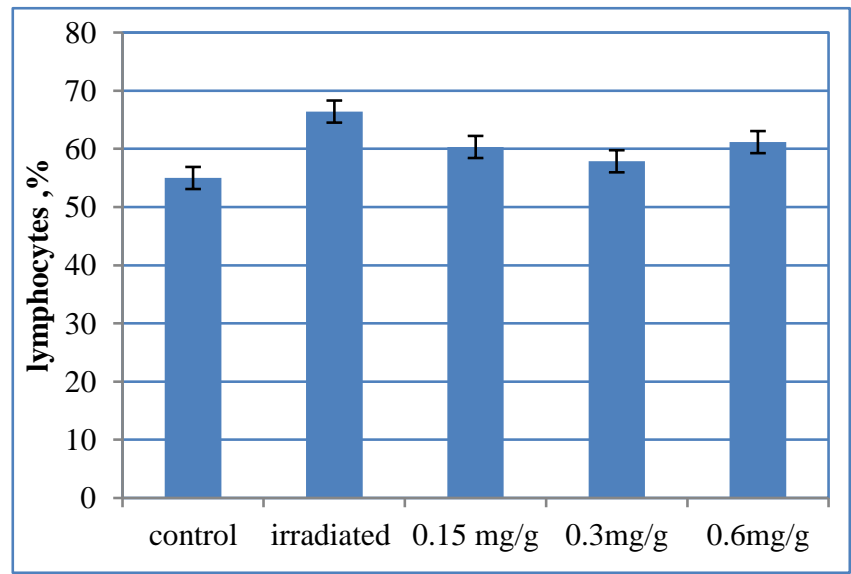

Fig. (8): The changes in the lymphocytes $(\%)$ as functions of gamma irradiation and post administration of increasing doses of Fusarium oxysporum extract (mg/g rat's body mass). Error bars indicate standard error of mean values. 


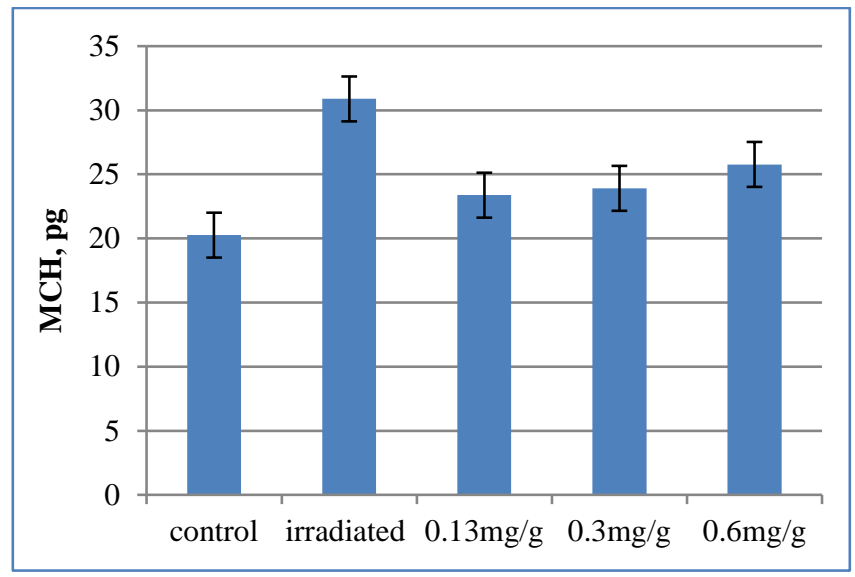

Fig. (9): The changes in the mean corpuscular haemoglobin (pg) as functions of gamma irradiation and post administration of increasing doses of Fusarium oxysporum extract (mg/ g rat's body mass). Error bars indicate standard error of mean values.

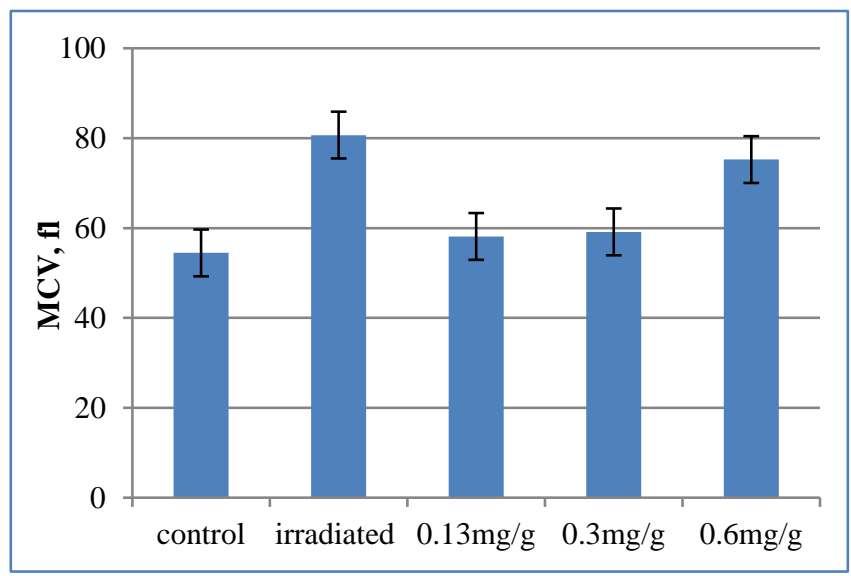

Fig. (10): The changes in the mean corpuscular volume (fl) as functions of gamma irradiation and post administration of increasing doses of Fusarium oxysporum extract (mg/ g rat's body mass). Error bars indicate standard error of mean values.

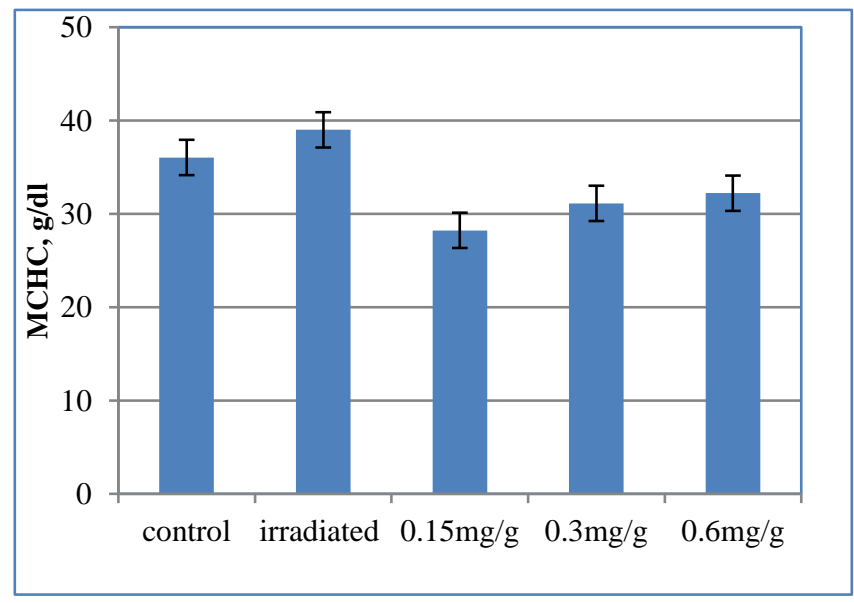

Fig. (11): The changes in the mean corpuscular haemoglobin concentration (g/dl) as functions of gamma irradiation and post administration of increasing doses of Fusarium oxysporum extract $(\mathrm{mg} / \mathrm{g}$ rat's body mass). Error bars indicate standard error of mean values.
The irradiation induced injures, in the most cases, started within the first week .[27] There were detectable decreases in RBCs, HGB , Ht, WBCs, platelets, Monocytes and segmented neutrophils in all rat groups exposed to $4 \mathrm{~Gy}$ gamma irradiation when compared to the positive control group. On the other hand, lymphocytes, $\mathrm{MCV}$, and $\mathrm{MCH}$ increased significantly as the rats exposed to the single irradiation dose, while MCHC indicated non-significant changes due to irradiation treatment (Fig. 11).

In this research, the value of $R^{2}$, almost in all relations, was near or greater than 0.8 , indicating a high degree of correlation between the observed and predicted values.

The injure effects of $\gamma$-radiation on the RBCs can be attributed to the suspension in erythrocytes' production in bone marrow, loss of cells from the circulation by haemorrhage or leakage through capillary walls and/or direct destruction of mature circulating cells. Nikishkin et al. [28] reported that increased permeability in the haemolytic process and the erythrocytes' membrane stability was major reason for the detected drop in RBCs count following $\gamma$-irradiation. According to Down et al.[29] , the haemolysis was the main cause of the developed anaemia following whole body $\gamma$-irradiation . Administration the FO extract post $\gamma$ - irradiation showed clear ameliorations in the RBCs count (Figure 1).

The reduction in haemoglobin content post $\gamma$-irradiation can be attributed to the disturbance in the haemoglobin molecule regeneration. This can be correlated to pronounced hyperferraemia after $\mathrm{y}$-irradiation [30], in addition to oxidation of haemoglobin molecule.[31]

On administering FO extract, the rats showed a significant increase in their blood haemoglobin levels as compared with the negative control group. These results are in a good agreement with those reported by Chlebovsky et al. [32]

The diminish in haemoglobin and haematocrite contents, (Figs. 2\&3), could be attributed to the reduction in RBCs count, and /or a results of erythropoiesis failure, injures of mature cells, escalation in plasma volume or the reduction in peripheral blood elements due to a bone marrow syndrome. [9,33,34]

A detectable diminishing in the total leucocytes count in the irradiated rats reached near $40 \%$ as compared to the positive control animals. Treating the irradiated rats with increasing doses of FO extract accompanied with non-significant enhancement in the WBCs, but the rate of cells regeneration was slower than the rate of leucocytolysis due to $\gamma$-rays injures. FO is assumed to have ameliorative role against severe reduction in blood 
leukocytes by screening injure of the bone marrow. Fig.(4). The decrease in WBCs count in the irradiated rats could be the result of radiation-induced lipid peroxidation, and damage of their cell membranes. In man, it was reported that the recovery of lymphocytes usually begins shortly after completion of irradiation treatment .The total lymphocyte counts can be restored to normal levels in less than $2 \mathrm{yr}$. The relatively slow recovery of cell mediated immunity after irradiation indicated that total lymphoid irradiation can be subjected to impact of long term immunosuppression.[35]

The decrease in platelets count is co-existed with a decrease in RBCs count (Fig 5). The whole-body single dose $\mathrm{y}$-irradiation can induce a direct destruction of mature circulating cells, loss of cells from the circulation by haemorrhage, or leakage through capillary walls and reduced cell production as stated before. [9] Sanzari et al.[1] suggested that radiation-induced coagulopathies and decreased platelet counts are present in animals exposed to the radiation doses up to $2 \mathrm{~Gy}$. The WBCs decreased significantly due to irradiation, as stated, and partially recovered with administration of FO extract, whereas the decrease in platelet counts did not show the same recover as the WBCs even past the extract treatment within the same period i.e. seven days. (Figs. 4 \&5). Irradiation can induce leucopenia. [37]

In differential leucocytes count, a significant decline in monocytes and segmented neutrophil percentages were detected in 4 Gy irradiated rat groups as compared to control values. In gamma irradiated rats and administering FO extract, there were pronounced increases in monocytes and segmented neutrophil percentages relative to the irradiated rats, but still lower than the control group animals. (Figs. 6\&7).

It is well known that the lymphocytes are an essential part of innate immunity, the early increase in their count post $\gamma$ irradiation could be mostly due to rapid recruitment of these cells from the bone marrow. Administration of FO extract accompanied with a detectable recovery, but not significant, in the lymphocytes percentage within 7 days (Fig. 8).

$\mathrm{MCV}$ and $\mathrm{MCH}$ increased significantly with irradiation doses compared to the control group, while $\mathrm{MCHC} \%$ did not change significantly in most treated groups (Figures 9-11). Similar trend was reported by Abojassim et. al.[38] to the most cases, the decrease in the values of the haematological parameters following radiation exposure can be also, attributed to their direct damage. [39] The cellular elements of the blood are particularly sensitive to oxidative stress since their plasma membranes contain a high percentage of polyunsaturated fatty acids.[40] IR has a sufficient amount of energy to induce physical symptomatology within minutes of exposure, appearing as the acute radiation syndrome (ARS). Hematopoietic cell loss was observed as early as 3 hours after the conclusion of radiation exposure, with a more profound complications observed at the 48-hour time point. [1]

However, the time needed for recovery of all the studied haematological parameters, in the whole, is very long. Consequently, the rate of repairing the disturbance took place in the blood components can be very low compared the rate of their damage. [39] Therefore, it is worth to state that the application of different doses of FO extract to the irradiated rats manifested a tendency towards recovery during the seven days from the administration onset and, mostly, the dose at $0.3 \mathrm{mg} / \mathrm{g}$ is characteristically the effective one as a radiation protective agent.

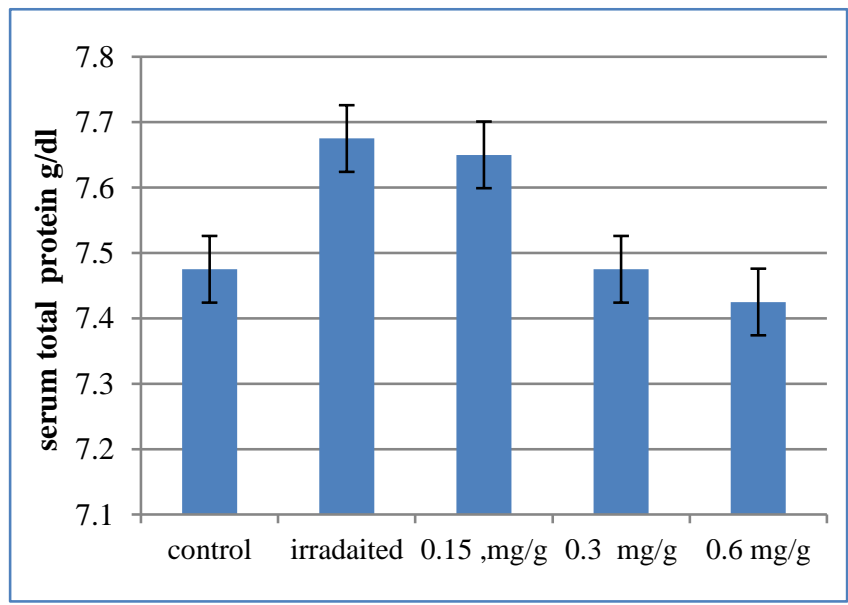

Fig. (12): The changes in the total serum protein (g/dl) as functions of gamma irradiation and post administration of increasing doses of Fusarium oxysporum extract (mg/ g rat's body mass). Error bars indicate standard error of mean values.

A detectable elevation in serum total protein levels in $\gamma$-irradiated rats was found to be $\sim 2.3 \%$, as compared with the corresponding control rats. This marked increase in total protein may be attributed to preexisting complicationsin vital biological processes e.g. dehydration, and/ or due to the change in the permeability of rats' tissues resulting in leakage of protein to the blood serum. Administration of FO extract post $\gamma$-irradiation showed a protective effect against $\gamma$-radiation disturbance in serum total proteins production and permeability (Fig. 12).

The hyperproteinemia after stimulation of gamma irradiation of the rats can occur mainly due to the increase in the concentration of total globulin, figure (13), whereby the raise in total globulins can be 
attributed to the elevation in $\alpha$ - globulin synthesis as impact of gamma irradiation. Globulin levels in serum of irradiated rats seemed to be rehabilitated and dropped near the control values as these irradiated rats were supplemented with FO extract at doses of $0.3 \mathrm{mg} / \mathrm{g}$ and $0.6 \mathrm{mg} / \mathrm{g}$.

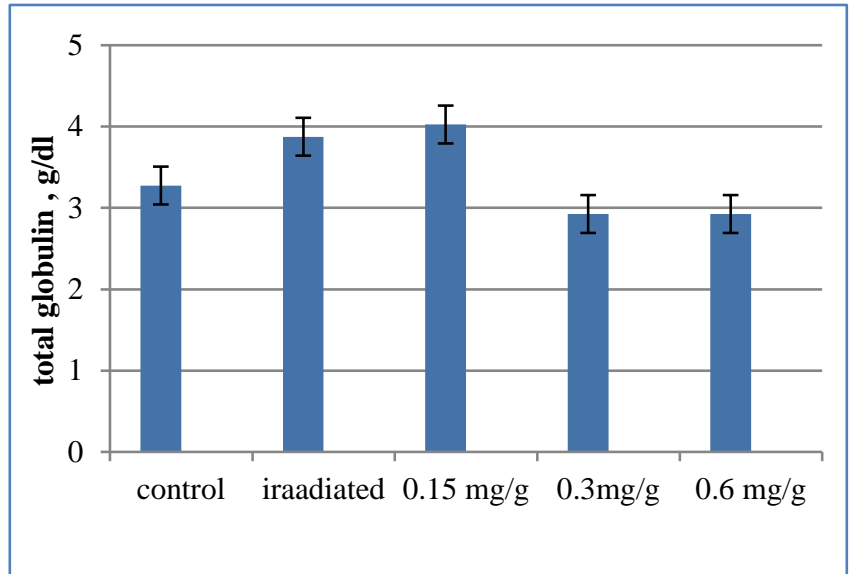

Fig. (13): The changes in the total globulin (g/dl) as functions of gamma irradiation and post administration of increasing doses of Fusarium oxysporum extract (mg/ g rat's body mass). Error bars indicate standard error of mean values.

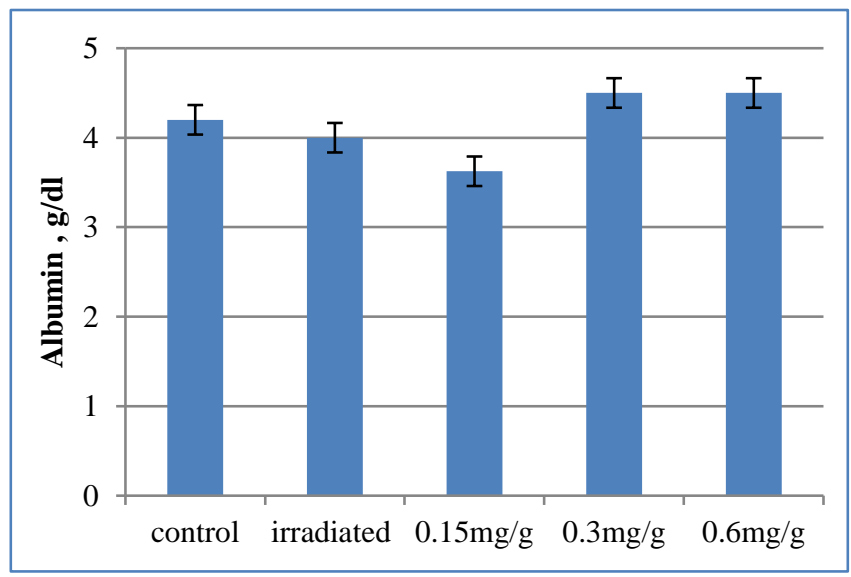

Fig. (14): The changes in the serum albumin (g/dl) as functions of gamma irradiation and post administration of increasing doses of Fusarium oxysporum extract (mg/g rat's body mass). Error bars indicate standard error of mean values.

The data presented in Figure (14) showed a slight decline in serum albumin levels in the $\gamma$-irradiated rats as compared with the corresponding control ones. The diminishing in the albumin concentration exist to the rats administrated $\mathrm{FO}$ at $0.15 \mathrm{mg} / \mathrm{g}$ body mass post irradiation. The decrease in the level of albumin concentration could be attributed to degradation in addition to the loss of albumin through the gastrointestinal tract.[42] Moreover, the interruptions of the lymphoid organs following $\gamma$ - irradiation was probably related to the drop in serum globulin levels.[30] However, rats administrated FO at dose $0.15 \mathrm{mg} / \mathrm{g}$ were unable to recover the dropped albumin values compared to its control levels i.e. the rate of albumin degradation is still greater than its rate of recovery. Whereas the rats administrated FO extract at doses of $0.3 \mathrm{mg} / \mathrm{g}$ and $0.6 \mathrm{mg} / \mathrm{g}$ post exposure to $\gamma$-radiation restored the albumin levels nearly to the control values or a little bit higher within one week, viz that the rate of recovery exceeded the rate of degradation.

It was reported that the water-extracted mycelial polysaccharide (WPS) from entophytic fungus Fusarium oxysporum species demonstrated antioxidant activity. [43,44] The protective effect of FO against the oxidative injures can attributed to various anti- toxicants that assumed to be found in FO extract, e.g. phenolic compounds, anthocyanins, flavonoid glycosides, procyanidins and others which are responsible for the observed antioxidant activity. In the fungi extract, these natural materials can detoxify the free radicals such as superoxide and hydroxyl radicals evoked due to gamma irradiation, consequently inhibiting lipid peroxidation and the other ionizing impacts. Similar explanations were reported for similar plant extracts.[45,46] This extract could also hinder the detrimental effects of free radicals by preventing the oxidation of cell membrane.[47] The data obtained demonstrated that FO extract ameliorated the tissue damage induced by whole body irradiation of rats as evidenced by improving most of the studied haematological parameters.

FO extract could alleviate the toxic impacts of ionizing radiation and thus it aids as a radioprotective in radiotherapy regimen.[2] Fusarium oxysporum extracts, as natural products, can be considered less or non-toxic with free radical scavenging capability, antioxidant capacity, immune stimulatory impacts and have the advantages, as biomaterials, over their synthetic counterparts.[27]

\section{CONCLUSION}

The analysis of the data of the present work assumed that injures due to $\mathrm{y}$-IR causes a significant reduction in pairs of biomedical parameters and blood components post the single irradiation dose, while the treatment with FO showed detectable improvements depending on the FO doses, which can be considered a potential health protection during exposure to irradiation. 
According to the obtained results, it can be concluded that the clinically reported injures in albino male rats due to the gamma irradiation exposure can be handed by FO administration, mainly, through the impacts of its antioxidant components. The radiation protective effect of FO extract could reduce the dependence on chemically based synthetic drugs, and subdue human exposure to chemical residues related to the side effects and toxicity as a result of administrating such medications. Nevertheless, Fusarium oxysporum extract administration still needs to be optimized in terms of the proper dosage and period of administration for human application.

Generally, natural materials can be securely applied for numerous human abnormalities due to irradiation exposures. They can focus on clinical traits to offer safer and more effective gamma irradiation protective capacity. However, extensive additional studies will be necessary before the results of such and similar works can be fully assessed. More researches and much effort should be considered and focused on authorizing protocols for medical management of radiation injuries based on natural products.

\section{ACKNOWLEDGMENT}

Authors would like to express their appreciation to the Radioisotopes Department, Egyptian Atomic Energy Authority for providing the possible facilities to produce this work.

\section{CONFLICT OF INTEREST}

Authors confirmed that they have no conflict of interest regarding the content of this article.

\section{REFERENCES}

[1] J.K.Sanzari, X. Steven Wan, G.S.Krigsfeld, A.J.Wroe, D. S. Gridley and A. R. Kennedy; The Effects of Gamma and Proton Radiation Exposure on Hematopoietic Cell Counts in the Ferret Model; Gravit. Space Res. 2013 Oct; 1(1): 79-94,(2013). $\quad$ PMCID: $\quad$ PMC4209750. NIHMSID: NIHMS584800.[Google Scholar].

[2] Sh., M. Abou-Zeid, B. E. EL-bialy, N. B. ELborai, H. O. Abu BakrElhadaryand A. Abdel Monsef;Radioprotective effect of Date syrup on radiation- induced damage in Rats ;SCiENTiFiCREpOrtS ，8:7423， 1-10,(2018). DOI:10.1038/s41598-018-25586-3
[3] E.J. Hall and A. Giaccia; Radiobiology for the radiologist.6th ed. (2008), Lippincott. Williams \& Wilkins, Philadelphia, PA [Google Scholar].

[4] D. Holl, D. Coelho, P.Weltin, J. Dufour, P.Gueulette, andEx. Bischoff; Vivo determination of the effect of whole-body exposure to fast neutrons on murine spleen cell viability and apoptosis; Radiation Research, 1543, 3 01306,(2000) [Crossref], [Web of Science ${ }^{\circledR}$ ], [Google Scholar].

[5] A. Onody, C. Csonka, Z. Giricz and P. Ferdinandy; Hyperlipidemia induced by a cholesterol-rich diet leads to enhanced peroxynitrite formation in rat hearts; Cardiovasc. Res. 58(3):663-670, (2003).

[6] T. Finkel andN.J. Holbrook; Oxidants, oxidative stress and biology of aging; Nature 408:239- 47, (2000).

[7] D.R. Spitz, E.I. Azzam, J.J. Li and D. Gius; Metabolic oxidation/reduction reactions and cellular responses to ionizing radiation: $\mathrm{A}$ unifying concept in stress response biology; Cancer Metast. Rev. 23:311-322, (2004).

[8] A. Berroud, A. Le-Roy andP. Voisin; Membrane oxidative damage induced by ionizing radiation detected by fluorescence polarization; Radiat. Environ. Biophy., 35:289295, (1996).

[9] Kh. Sh. Azab, M. Bashandy, M. Salem, O. Ahmed, Z. Tawfik and H. Helal; Royal jelly modulates oxidative stress and tissue injury in gamma irradiated male Wister Albino rats; $\mathrm{N}$ Am J Med Sci.; Jun, 3(6): 268-276,(2011). doi: 10.4297/najms.2011.3268

[10] E. Mihandoost, A. Shirazi, S. R. MahdaviandA. Aliasgharzadeh; Consequences of LethalWhole-Body Gamma Radiation and Possible Ameliorative Role of Melatonin;the Scientific World Journal, volume 2014, Article ID 621570, 9 pages, (2014). Hindawi Publishing Corporation.

http://dx.doi.org/10.1155/2014/621570.

[11] M. A. K. Abdelhalim andS. A. A. Moussa; The biochemical changes in rats' blood serum levels exposed to different gamma radiation doses. African Journal of Pharmacy and 
Pharmacology; Vol. 7(15), pp. 785-792, 22 April, (2013).

DOI 10.5897/AJPP2013.3434 ISSN 1996-0816

(C) 2013 Academic Journals

[12] P. Ma`skovi'c, S. Soluji'c, V. Mihailovi'c, et al.; Phenolic compounds and biological activity of Kitaibeliavitifolia;Journal of Medicinal Food, vol. 14, no. 12, pp. 1617-1623, (2011).

[13] E. Grotewold;The Science of Flavonoids, Ohio State University, Columbus, Ohio, USA, (2006).

[14] T. Arif, J. D. Bhosale, N. Kumar, et al. ; Natural products - antifungal agents derived from plants;Journal of Asian NaturalProducts Research, vol. 11, no. 7, pp. 621-638, (2009).

[15] M. Friedman; Overview of antibacterial, antitoxin, antiviral, and antifungal activities of tea flavonoids and teas; MolecularNutrition and Food Research, vol. 51, no. 1, pp. 116-134, (2007).

[16] B. Ozc,elik, M. Kartal and I. Orhan; Cytotoxicity, antiviral and antimicrobial activities of alkaloids, flavonoids, and phenolic acids;Pharmaceutical Biology, vol. 49, no. 4, pp. 396-402, (2011).

[17] M. Zabka andR. Pavela; Antifungal efficacy of some natural phenolic compounds against significant pathogenic and toxinogenic filamentous fungi;Chemosphere, vol. 93, no. 6, pp. 1051-1056, (2013).

[18] A. Mansouri, G. Embarek, E. Kokkalou andP. Kefalas; Phenolic profile and antioxidant activity of the Algerian ripe date palm fruit (Phoenix dactylifera); Food Chem. 89: 411420, (2005).

[19] L. Gu, M. A. Kelm, J. F. Hammerstone, G. Beecher J. Holden, D. Haytowitz and R. L. Prior; Screening of foods containing proanthocyanidins and their structural characterization using LCMS/ MS and thiolytic degradation;J. Agric. Food Chem., 51: 75137521, (2003).

[20] S. Aydoğan, B. Erdağ andL. Aktaş; Bioaccumulation and oxidative stress impact of $\mathrm{Pb}, \mathrm{Ni}, \mathrm{Cu}$, and $\mathrm{Cr}$ heavy metals in two bryophyte species, Pleurochaete squarrosa and Timmiella barbuloides; Turkish Journal of
Botany. The Scientific and Technological Research Council of Turkey, 41(5), pp. 464475, (2017).

[21] N., Martins, L. Barros, M. Henriques, S. Silva andI. C. F. R. Ferreira; Review Article: In Vivo Anti-Candida Activity of Phenolic Extracts and Compounds: Future Perspectives Focusing on Effective Clinical Interventions;BioMed Research International, vol. 2015, Article ID 247382, 14 pages,(2015). http://dx.doi.org/10.1155/2015/247382.

[22] N. Salhi, S. Ah. M. Saghir, V. Terzi, I. Brahmi, N. Ghedairi and S. Bissati; Antifungal Activity of Aqueous Extracts of Some Dominant Algerian Medicinal Plants;BioMed Research International,vol. 2017, Article ID 7526291, 6 pages, (2017).

https://doi.org/10.1155/2017/7526291.

[23] S.S. Wang, D.M. Wang, W.J. Pu, and D.W. Li; Phytochemical profiles, antioxidant and antimicrobial activities of three Potentilla species; BMC Complementary and Alternative Medicine, vol. 13, article 321, (2013).

[24] N.C. Jain;Schalm's Veterinary Haematology, 4th ed. Lea and Fabiger, Philadelphia, (1986).

[25] B.M., Mitruka andH. Rawnsley; Clinical, biochemical and haematological references values in normal experimental animals; Masson Publishing USA Inc., pp. 53-54. (1977)

[26] A. Kaplan and J. Savory, Evaluation of a cellulose acetate electrophoresis system for serum protein fraction; Clinical chemistry, 11,10 937-942,(1965). DOI 1093

[27] M. Oladi, A. Sazgarnia, M.R. G. Nasiri, M. Amrollahi,H. Parhiz and M. Ramezani ; In vivo Time-Dependent Radio-Protective Effect of Lycopene Against Whole-Body Gamma Radiation in Mice; Iran Red Crescent Med J., February; 19(2): e19624, 8 pages, (2017) . doi: $10.5812 /$ ircmj.19624.

[28] I.A. Nikishkin, V.N. Sukolinskij, O.V. Kovaleva, N.I. Raspopova andV.K. Naumenko; Enzyme of erythrocyte membrane protection under the combined effect of an antioxidant complex and acute irradiation; Radiobiologia, 32(5): 738,(1992). 
[29] J. Down, A. Berman and P. Mauch; Late complications following total body irradiation and bone marrow rescue in mice: Predominance of glomerular nephropathy and haemolytic anaemia; Int. J. of Rad. Biol.,57(3): 551, (1990).

[30] A.A. Saad El-din, M. Abdel-Baset, H.M. Roushdy andM.A. Fadel; Effect of low fast neutron doses on the blood gases, buffer capacity and electrophoretic pattern of haemoglobin of mice; The first conference on biophysics, Cairo University, 289: 253, (1988).

[31] Z. Szweda- Lewandowska, M. Puchata andW. Leyko; Effects of gamma irradiation on the structure and function of human haemoglobin; Rad. Res. 65(1): 50, (1976).

[32] O. Chlebovsky, M. Praslicka, K. Chlebovska, I. Kalina and I. Datelinka; Changes in the blood and haemopoiesis of rats exposed to exponentially decreasing does rates of continuous gamma irradiation. i. Peripheral blood count; Radiobiol. Radiother. (Berl)., 24(1): 35; (1983).

[33] N. Malhotra and P.N. Srivastava; Haematological effects after administration of radiophosphorus in mice: Fractionated irradiation and late effects; Radiobiol Radiother. ,19:347-350, (1978). [PubMed] [Google Scholar].

[34] E.L. Alpen, D.M. Jones, H.H. Hechter andV.P. Bond; The comparative biological response of $\operatorname{dogs}$ to $250 \mathrm{kVp}$ and $100 \mathrm{kVp} \mathrm{X}$-rays; Radiology.,70:541-550,(1958). [PubMed] [Google Scholar]

[35] Z. Fuks, S. Strober, A.M. Bobrove, T. Sasazuki, A. McMichaeland H.S. Kaplan; Long Term Effects of Radiation on $\mathrm{T}$ and $\mathrm{B}$ Lymphocytes in Peripheral Blood of Patients with Hodgkin's Disease; The Journal of Clinical Investigation, vol. 58, October , 803-814, (1976).

[36] A.P. Casarett, editor; Radiation biology. Englewood Cliffs, NJ: Prentice Hall Inc; pp. 158-159, (1968). [Google Scholar]

[37] S. Mishima, K. Saito, H. Maruyama, M. Inoue, T. Yamashita and Y. Gu; Antioxidant and immuno-enhancing effects of Echinacea purpurea; Biol. Pharm. Bull., 27: 1004-1009, (2004).

[38] A.A. Abojassim, H.S. Jaffat andA.B. Hassan; Effects of Gamma Radiation on Some Hematological Parameters in Female Rats; ISJ Theoretical \& Applied Science, 05 (25): 101109; (2015). doi: http://dx.doi.org/10.15863/TAS.2015.05.25.19.

[39] Q. Kh. Al-DulameySh T. Aldabag and R.R. Shafeek; Gamma Ray Effects on White Blood Cells of Male Mice; NeuroQuantology, August, 18 (8), 19-23, (2020). doi: 10.14704/nq.2020.18.8.NQ20200.

[40] G.L. Heda andA.L. Bhatia;Haemocytometrical changes in Swiss albino mice after intrauterine low level HTO exposure; Proc Asian Reg. Conf. Med. Phys.; 390,(1986). [Google Scholar]

[41] B.P. Chew andJ.S. Park; Carotenoid action on the immune response; J. Nutr., 134:257S-261S, (2004). [PubMed] [Google Scholar].

[42] M.M. Abbady; Biochemical changes in irradiated animals exposed to some environmental pollutants; Ph.D. Thesis, Fac. of Science, Ain Shams Univ. (1994).

[43] P. Li, C. Luo, W. Sun, S. Lu, Y. Mou, Y. Peng andL. Zhou;In vitro antioxidant activities of polysaccharides from endophytic fungus Fusarium oxysporum Dzf17; Afr. J. Microbiol. Res. 5, 5990-5993, (2011).

[44] P. Li, S. Lu, T. Shan Y. Mou, Y. Li, W. Sun andL. Zhou; Extraction Optimization of WaterExtracted Mycelial Polysaccharide from Endophytic Fungus Fusarium oxysporum Dzf17 by Response Surface Methodology ; Int. J. Mol. Sci., 13, 5441-5453, (2012). doi:10.3390/ijms13055441

[45] A. Abdul andA. Allaith; Antioxidant activity of Bahraini date palm (Phoenix dactylifera $L$.)fruit of various cultivars;Intern. J. Food Sci. Technol. 43, 1033-1040, (2008).

[46] P. K. Vayalil; Date fruits (Phoenix dactylifera Linn): an emerging medicinal food;Crit. Rev. Food Sci. Nutr. 52, 249-271, (2012). 
[47] N. M. Selim, S. S. El-Hawary, S.M. El Zalabani, R. N. Shamma. N. El SayedMahdy, N. H. Sherif ,H. A. Fahmy, M. H. Mekkawy, Y. Abdelaziz andM. Sobeh; Impact of Washingtoniarobusta Leaves on Gamma
Irradiation-Induced Hepatotoxicity in Rats and Correlation with STING Pathway and Phenolic Composition; Pharmaceuticals,13,320, (2020). doi:10.3390/ph1310032. 